\title{
Modelling habitat associations of the common spider conch in the Cocos (Keeling) Islands
}

\author{
L. M. Bellchambers ${ }^{1, *}$, J. J Meeuwig ${ }^{2}$, S. N. Evans ${ }^{1}$, P. Legendre ${ }^{3}$ \\ ${ }^{1}$ Department of Fisheries, Western Australian Fisheries and Marine Research Laboratories, North Beach, \\ Western Australia 6920, Australia \\ ${ }^{2}$ School of Animal Biology and Centre for Marine Futures, Oceans Institute, The University of Western Australia, Crawley, \\ Western Australia 6009, Australia \\ ${ }^{3}$ Département de Sciences Biologiques, Université de Montréal, Montréal, Québec, Canada H3C 3J7
}

\begin{abstract}
The type and configuration of benthic habitats can influence community structure of marine fauna and the effectiveness of management actions, such as spatial closures. We quantified the relationship between the distribution and density of Lambis lambis, an exploited marine gastropod, and available benthic habitats at the Cocos (Keeling) Islands. We used 3 modelling approaches to develop a model of the density of $L$. lambis as a function of habitat: conventional polynomial regression, Moran's eigenvector maps (MEM) and variance partitioning. Distribution and abundance of L. lambis was not uniform throughout the lagoon. Both the amount and configuration of habitat influenced L. lambis density; the highest densities were associated with moderate levels of hard macroalgae and submassive corals, and the lowest densities with seagrass and relict coral. These results illustrate that incorporating information on the distribution and patchiness of preferred habitats is essential to ensure that appropriate habitats are included in the design and implementation of long-term monitoring programs and management tools such as spatial closures.
\end{abstract}

KEY WORDS: Lambis lambis $\cdot$ Habitat associations $\cdot$ Spatial ecology

Resale or republication not permitted without written consent of the publisher

\section{INTRODUCTION}

Knowledge of the spatial distributions of marine populations is fundamental to understanding their ecology and has direct relevance to fisheries and conservation management (Freeman \& Rogers 2003, Bellchambers et al. 2010, Harper et al. 2010, Bejarano et al. 2011). The recognition that fisheries and conservation management should encompass the protection of habitats is increasing, as the amount and configuration of habitat can influence the faunal communities it supports (Bellchambers et al. 2010, Moore et al. 2010). The first step in this process is to develop a good understanding of the relationship between the density of the exploited species and the spatial distribution of available habitat types (Harper et al. 2010, Moore et al. 2010, Bejarano et al. 2011). Previous studies have illustrated that the abundance and distribution of marine molluscs, e.g. Strombus gigas, is determined by the availability of preferred habitats (Stoner \& Waite 1990, Tewfik \& Béné 2000, Tewfik \& Guzman 2003).

The common spider conch Lambis lambis is another strombid gastropod that is harvested by artisanal fisheries. It is found throughout the Indo-Pacific from Tonga to the east coast of Africa. A number of studies have reported the distribution of L. lambis (Abbott 1961); however the basic biology and ecology of the species is largely unstudied. Remains of $L$. lambis from Lene Hara Cave, East Timor, date back to ca. 35000 years before present (YBP), showing a long history of capture in the Indo-Pacific ( $\mathrm{O}^{\prime}$ Connor et al. 2002). Lambis lambis, known locally as gong gong, is regarded as a delicacy by the Malays of the Australian territory of the Cocos (Keeling) Islands in the Indian Ocean, where it is extensively fished using artisanal techniques. Although how long the Cocos Malays have 
been collecting L. lambis is not known, surveys indicate that collecting only became popular in the last 2 decades (Lincoln-Smith et al. 1993). The fishery is currently unregulated, but new fishing guidelines are being introduced. Whether these new guidelines will ensure the sustainability of the Cocos (Keeling) Islands L. lambis fishery remains uncertain.

Lambis lambis shares similarities with Strombus gigas, which has been severely overfished throughout the tropical and subtropical waters of the Caribbean; diverse stock management regulations have been in place in Caribbean nations since the 1970s (Theile 2003). Factors that contribute to the sensitivity of L. lambis to over-fishing include probable late maturation, shallow water habitat, slow movement, and tendency to aggregate in shallow water for spawning. Previous studies have suggested that the distribution and abundance of $S$. gigas are dependent on the distribution of the habitats used by the species, as well as on the processes that are inherent to their life cycle such as recruitment, migration and mortality (Stoner \& Waite 1990, Stoner 2003). Assessing the sustainability of fishing and management practises on L. lambis at the Cocos (Keeling) Islands requires an understanding of its distribution and density in relation to available habitats. The extent and location of these habitats in relation to the fishing community can also provide information on patterns of exploitation and assist in implementing management strategies such as temporal and spatial closures.

In this study, we used several modelling approaches to explore the relationships of Lambis lambis density within the lagoon at the Cocos (Keeling) Islands with both habitat and distance to the main fishing village. We used (1) conventional polynomial regression, (2) Moran's eigenvector maps (MEM) that quantify underlying spatial structure through the production of spa- tial eigenfunctions and then (3) variance partitioning to combine the habitat variables with the MEM spatial eigenfunctions such that variation in L. lambis density can be apportioned between habitat variables and the underlying spatial structure of the sampling design. The use of these 3 statistical modelling approaches allowed us to develop a model of the density of L. lambis as a function of habitat and, more importantly, to understand the way in which the underlying spatial structure combines with habitat to determine the density of $L$. lambis within the lagoon.

\section{MATERIAL AND METHODS}

The Cocos (Keeling) Islands are located in the Indian Ocean $\left(12^{\circ} 12^{\prime} \mathrm{S}, 9^{\circ} 54^{\prime} \mathrm{E}\right)$ (Fig. 1). The group is comprised of 2 separate coral atolls, consisting of 27 islands. The southern atoll consists of 26 islands surrounding a shallow lagoon, 2 of which are inhabited by a total population of $\sim 600$ people.

In 2008, the density of Lambis lambis in these islands was surveyed at 67 sites. Sites were chosen by dividing the lagoon into 40 squares of 1 by 1 geographical minutes. In each, up to 3 random sampling sites were located. At each of the sampling sites, surveys were conducted by divers on snorkel or SCUBA along 2 parallel belt transects $100 \mathrm{~m}$ long and $2 \mathrm{~m}$ wide, $\sim 10 \mathrm{~m}$ apart. The total number of $L$. lambis and the percent cover of each habitat type (Table 1) were recorded along the $100 \mathrm{~m}$ transect. In this study only adult $L$. lambis were recorded, as juveniles are cryptic and buried in the sand. The $\pm \mathrm{SD}$ of L. lambis were calculated for each site from the 2 replicate transects. Mean percentage cover for each habitat class was similarly calculated from the 2 replicate transects.

Modelling density using polynomial regression. Lambis lambis density was transformed as $\log _{10}(x+1)$ given the positive skew in the data and the presence of many zero values. Habitat data were centred by subtracting the value for each site from the mean value across all 67 sites for each habitat class (Legendre \& Legendre 1998). The second and third order monomials were then calculated using the $\mathrm{R}$ function poly which provides orthogonal monomials (R Development Core Team 2009). Polynomials allow the statistical model to account for nonlinear responses of the dependent variable in regression models (Legendre \& Legendre 1998), which is appropriate for
Fig. 1. Cocos (Keeling) Islands. Location relative to (a) Australia and (b) the central lagoon. $\bullet$ : sites surveyed for Lambis lambis 
Table 1. Lambis lambis. Descriptive statistics for (a) individual counts and distribution from inhabited island and (b) habitat variables along transects. Habitat genera are not a comprehensive list but represent the dominant components of each habitat type. Massive corals were defined as those solid and similar in shape in all directions, while submassive coral were less than, or not quite, solid and similar in shape in all directions. Hard macroalgae: algae that had a brittle or mineralised appearance

\begin{tabular}{|c|c|c|c|c|c|}
\hline Variable & Dominant characteristics & Mean & $\mathrm{SD}$ & Min. & Max. \\
\hline \multicolumn{6}{|c|}{ (a) Species density and distribution } \\
\hline \multicolumn{2}{|c|}{ No. of individuals per $200 \mathrm{~m}^{2}$} & 13.5 & 22.9 & 0.0 & 109 \\
\hline \multicolumn{2}{|c|}{ Minimum distance (m) } & 3368 & 2392 & 268 & 7777 \\
\hline \multicolumn{6}{|c|}{ (b) Habitat variables (\% coverage) } \\
\hline \multicolumn{2}{|c|}{ Sand } & 37.1 & 22.1 & 1.3 & 98.1 \\
\hline \multicolumn{2}{|l|}{ Sand and rubble } & 6.5 & 10.7 & 0.0 & 35.0 \\
\hline Rubble & Limestone rubble & 5.9 & 9.5 & 0.0 & 40.0 \\
\hline Seagrass & $\begin{array}{l}\text { Thallasia sp., } \\
\text { Thalassodendron sp. }\end{array}$ & 6.3 & 14.3 & 0.0 & 90.6 \\
\hline Macroalgae & $\begin{array}{l}\text { Hydroclathrus sp., } \\
\text { Padina sp., Caulerpa sp. }\end{array}$ & 13.3 & 16.7 & 0.0 & 73.8 \\
\hline Hard macroalgae & Acanthophora sp. & 11.8 & 13.1 & 0.0 & 56.3 \\
\hline Filamentous algae & & 4.6 & 7.6 & 0.0 & 35.6 \\
\hline Massive coral & $\begin{array}{l}\text { Porites sp., Pavona sp., } \\
\text { Favia sp. }\end{array}$ & 3.0 & 5.3 & 0.0 & 23.1 \\
\hline Branching coral & Acropora sp. & 4.5 & 9.9 & 0.0 & 40.6 \\
\hline Submassive coral & $\begin{array}{l}\text { Favia sp., Pocillopora sp., } \\
\text { Favites sp., Porites sp. }\end{array}$ & 5.2 & 7.4 & 0.0 & 31.9 \\
\hline Relict coral & Old eroded limestone reef & 1.7 & 4.3 & 0.0 & 25.0 \\
\hline
\end{tabular}

varies, with large periods indicating variation at larger spatial scales and short periods indicating variation at smaller spatial scales (Borcard \& Legendre 2002). They can be used to model the spatial structure of single response variables, as in the present study, or multivariate (multi-species) data tables, thus allowing the underlying spatial structure to be separated from the influence of environmental variables, such as the habitat variables in this study. The types of MEM variables computed in the present study were formerly called principal coordinates of neighbour matrices (PCNM, Borcard \& Legendre 2002, Borcard et al. 2004, Dray et al. 2006). The relationship between the log of Lambis lambis density and the spatial location of the sampling sites was tested using the function quickPCNM from the 'PCNM' R-language library (version 1.9, 2009, http://r-forge.r-project.org/ R/?group_id=195). As there was no significant linear trend in the response data, the data was not detrended prior to MEM analysis. A set of 17 MEM eigenfunctions modelling positive spatial correlation was used for modelling. Forward selection was used again habitat modelling. Minimum distance to the fishing village was used untransformed in models. Forward selection of explanatory variables in linear regression, with permutation tests, was carried out using the function forward.sel of the 'packfor' R-language package (version 0.0-9, 2007, http://r-forge.r-project.org/ $\mathrm{R} /$ ?group_id=195) with $\mathrm{p} \leq 0.10$ to ensure eventual consideration of variables nearly significant at the usual $\mathrm{p} \leq 0.05$ level. The regression $\mathrm{R}$ function $\mathrm{Im}$ was used to test the relationship between $L$. lambis density and distance to village as well as the degree to which inclusion of distance with the selected habitat variables improved model fit. Goodness-of-fit was assessed by the adjusted $R^{2}\left(R_{\text {adj }}^{2}\right)$ to control for varying numbers of variables within the models (Ohtani 2000).

Modelling density using MEM analysis. MEM eigenfunctions represent a spectral decomposition of the spatial relationships among the sampling locations at all scales, given the sampling design. Effectively, they are a series of sinusoidal waves with decreasing period representing the distances between sampling locations arranged as a straight line (Borcard \& Legendre 2002). They provide a relative measure of the spatial scale over which the response variable through the $\mathrm{R}$ function forward.sel with $\mathrm{p} \leq 0.10$ to determine which of the MEM eigenfunctions were correlated with the log of L. lambis density.

Combining habitat variables with MEMS. The selected habitat variables and all MEMs were combined into a single model so that the variation of the overall model could be partitioned between the environmental and spatial explanatory tables (Borcard et al. 1992, Peres-Neto et al. 2006) using the varpart function of the community ecology R-language package 'Vegan' (version 1.15-2, 2009, http://CRAN.R-project. org/package=vegan). Such variation partitioning is used to assess the contribution of environmental variables independent of underlying spatial structure as well as reducing the probability of a Type 1 error when assessing environmental variables alone, when spatial autocorrelation is present (Peres-Neto \& Legendre 2010). Correlations between the selected habitat variables and the MEMs selected by forward.sel were evaluated using the R function cor in order to identify the spatial scales at which habitat categories vary. The predicted distribution of Lambis lambis based on the combined model of habitat variables and MEM was then generated. 
Table 2. Results of forward selection indicating the change in the coefficient of determination $\left(\mathrm{R}^{2}\right)$ after accepting new habitat variables in the environmental model, as well as the cumulative and adjusted $\mathrm{R}^{2}$, and statistical results for the additional effect of the newly accepted variables. Order refers to whether the variable is a first or second order polynomial and sign refers to the direction of the relationship

\begin{tabular}{|lrrrrrrr|}
\hline & $\begin{array}{c}\mathrm{R}^{2} \\
(\%)\end{array}$ & $\begin{array}{c}\mathrm{R}^{2}{ }_{\text {cum }} \\
(\%)\end{array}$ & $\begin{array}{c}\text { Adj } \mathrm{R}^{2} \text { cum } \\
(\%)\end{array}$ & $F$ & $\mathrm{p}$ & Order & Sign \\
\hline Hard macroalgae & 18.8 & 18.8 & 17.5 & 13.9 & 0.002 & 2nd & + \\
Submassive coral & 10.6 & 29.5 & 27.1 & 8.9 & 0.004 & 2nd & + \\
Seagrass & 5.8 & 35.2 & 31.9 & 5.2 & 0.039 & $1 \mathrm{st}$ & - \\
Relict coral & 6.4 & 41.6 & 37.5 & 6.3 & 0.012 & $1 \mathrm{st}$ & - \\
\hline
\end{tabular}

adjusted for the number of variables was $51 \%$. Variance portioning indicated that nearly half $(\sim 21 \%)$ of the variation was explained jointly by the habitat variables and the MEMs. Habitat-related processes independent of spatial location accounted for $17 \%$ of the adjusted variability, while spatial location independent of habitat accounted for $13 \%$ of the adjusted variability in the $\log$ of $L$. lambis density. The shared $21 \%$ of the variation reflects the correlation between the habitat variables and the MEMs. Relict corals were correlated with MEM4 and

\section{RESULTS}

Lambis lambis were observed at 51 of the 67 sites $(82 \%)$ and ranged in abundance from 0 to 109 individuals in an area of $200 \mathrm{~m}^{2}$ (mean $\pm \mathrm{SE}=13.5 \pm 2.9 \mathrm{SE}$ ind. per $200 \mathrm{~m}^{2}$; Table 1). Habitats were dominated by sand, sand and rubble, or rubble, which collectively comprised $51.3 \%$ of the surveyed areas (Table 1), with any given site having a mix of habitat types. Algae and seagrass were less common, covering 29.7 and $6.3 \%$ of the area respectively. Live coral covered $\sim 12.7 \%$ of the area, with relict coral contributing a further $1.7 \%$. The mean distance between the surveyed sites and the main village from which most fishing for $L$. lambis occurs was $3.4 \mathrm{~km}$, and it ranged from $268 \mathrm{~m}$ to $7.8 \mathrm{~km}$ (Table 1).

Lambis lambis density was predicted by 4 of the first and second order habitat monomials (Table 2). The relationship between $L$. lambis density and hard macroalgae and submassive coral was quadratic with peak densities occurring at moderate values of these 2 habitat variables. L. lambis density was also linearly and negatively related to both seagrass and relict coral. Combined, these 4 variables accounted for $41.6 \%$ of the variation in L. lambis density (Table 2). There was no relationship between L. lambis density and distance to the village either when distance was considered alone $(p=0.84)$ or included in the habitat model $(\mathrm{p}=0.61)$.

Lambis lambis density was also spatially structured. The MEM analysis identified 4 MEMs out of the 17 possible eigenvectors, accounting for $37 \%$ of the variation in L. lambis density (Table 3). These MEMs captured spatial structure at a relatively coarse scale (MEM 4) as well as at moderate (MEM 9) and finer scales (MEMs 12 and 13), but not at the coarsest (MEMs < 4) or finest (MEMs > 13) scales modelling positive spatial autocorrelation.

The variance in Lambis lambis density explained by both the selected habitat variables and MEMs and
MEM9 and as such occurred at relatively coarse and moderate scales. Submassive corals were only correlated with MEM9 and as such appeared spatially structured at a moderate scale. Hard macroalgae was correlated only with MEM12 and thus appeared to be spatially structured at a moderate scale. Seagrass, which had the weakest relationship with $L$. lambis density (Table 2), was distributed at a moderate spatial scale (MEM9) but was the only habitat variable to be correlated with the relatively fine-scaled MEM13 (Table 4). This combined model accounted for the greatest amount of variation in L. lambis density and allowed us to predict the relative density of L. lambis across the lagoon (Fig. 2).

Table 3. Results of forward selection indicating the change in the coefficient of determination $\left(\mathrm{R}^{2}\right)$ after accepting a new Moran's eigenvector map (MEM) eigenfunction in the spatial model, as well as the cumulative and adjusted $\mathrm{R}^{2}$, and statistical results for the additional effect of the newly accepted variables

\begin{tabular}{|lrcccc|}
\hline MEM & $\mathrm{R}^{2}(\%)$ & $\mathrm{R}_{\text {cum }}^{2}(\%)$ & $\operatorname{Adj~}_{\text {cum }}{ }_{\text {co }}(\%)$ & $\mathrm{F}$ & $\mathrm{p}$ \\
\hline V4 & 11.5 & 11.5 & 10.0 & 7.8 & 0.008 \\
V12 & 10.1 & 21.6 & 18.9 & 7.6 & 0.007 \\
V9 & 9.6 & 31.2 & 27.6 & 8.1 & 0.008 \\
V13 & 5.8 & 37.0 & 32.6 & 5.2 & 0.021 \\
\hline
\end{tabular}

Table 4. Correlations between the selected habitat variables and Moran's eigenvector map (MEM) eigenfunctions. ${ }^{* *} \mathrm{p} \leq 0.001,{ }^{*} \mathrm{p} \leq 0.05$

\begin{tabular}{|lcccc|}
\hline MEM & Seagrass & $\begin{array}{c}\text { Hard } \\
\text { macroalgae }\end{array}$ & $\begin{array}{c}\text { Submassive } \\
\text { coral }\end{array}$ & $\begin{array}{c}\text { Relict } \\
\text { coral }\end{array}$ \\
\hline V4 & 0.035 & 0.168 & -0.142 & $0.484^{* *}$ \\
V9 & $0.290^{* *}$ & 0.094 & $0.232^{*}$ & $0.223^{*}$ \\
V12 & -0.119 & $-0.214^{*}$ & -0.089 & 0.064 \\
V13 & $0.250^{* *}$ & 0.077 & -0.008 & 0.009 \\
\hline
\end{tabular}



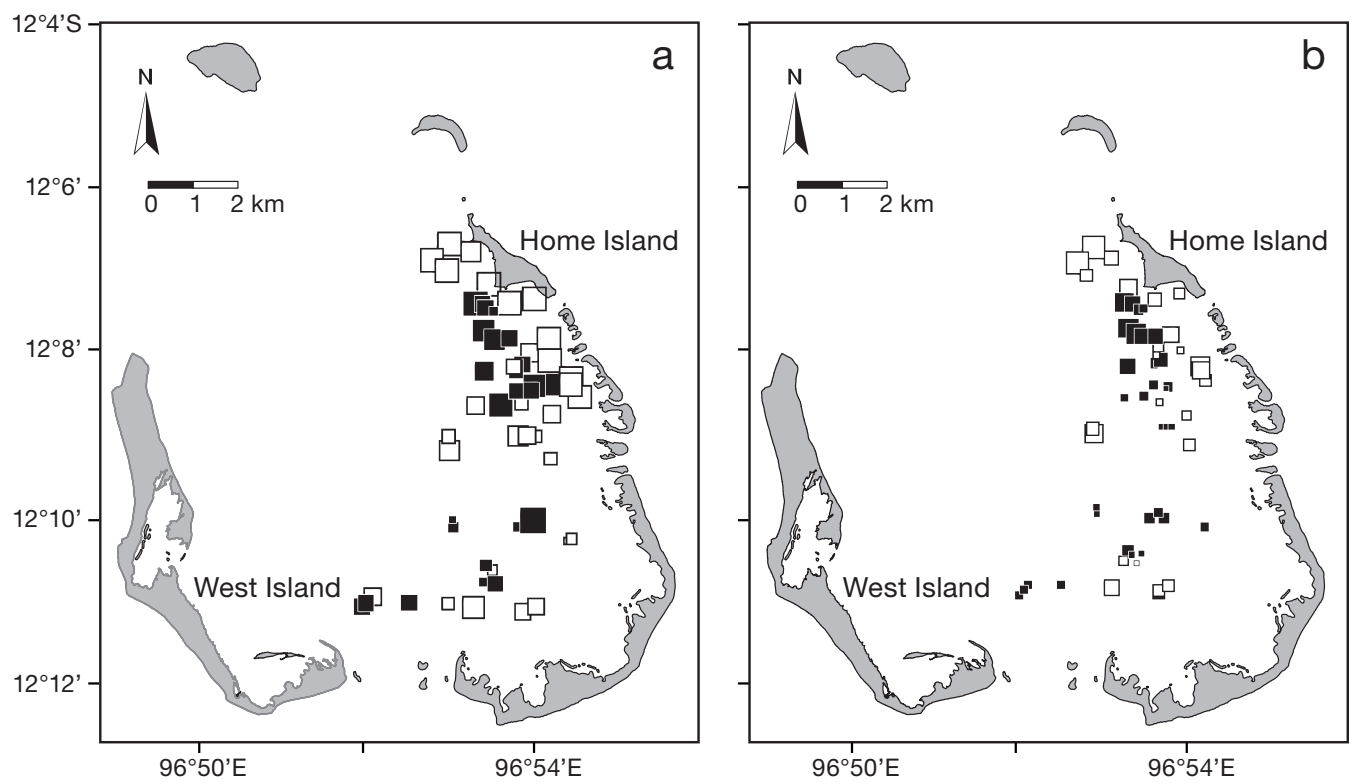

Fig. 2. Lambis lambis. (a) Observed and (b) predicted densities of L. lambis from the combined model. Square sizes are proportional to the associated values of positive (black) and negative (white) densities

\section{DISCUSSION}

The distribution of Lambis lambis was not uniform throughout the lagoon at Cocos (Keeling) Islands. Peak L. lambis densities were associated with moderate values of hard macroalgae and submassive corals and negatively correlated with seagrass and relict coral. The highest densities of L. lambis were observed in the northeastern part of the lagoon where the habitat consisted of sand, macroalgae and hard macroalgae, while the lowest densities occurred in shallow, sand-dominated areas and also in seagrass. The centre of the lagoon is unsuitable habitat for L. lambis as it is dominated by branching coral, Acropora sp.

No previous studies on habitat associations of Lambis sp. exist; however, a number of studies have shown that the density of various strombids is correlated to habitat (Torres Rosado 1987, Tewfik \& Béné 2003, Tewfik \& Guzman 2003). Densities of adult Strombus gigas were highest in algal plains and seagrass habitats in both the Turks and Caicos Islands (Tewfik \& Béné 2003) and at Bocas del Toro in Panama (Tewfik \& Guzman 2003) while the highest densities in La Parguera, Puerto Rico, were in rubble habitats (Torres Rosado 1987). Densities of the milk conch, S. costatus, at the same locations in Panama (Tewfik \& Guzman 2003) and Puerto Rico were highest in rubble habitats (Torres Rosado 1987). These studies illustrate that habitat plays an important role in determining the distribution and abundance of strombids throughout their geographic range.

In our study, Lambis lambis density was negatively correlated with seagrass, a surprising result given the importance of seagrass as a habitat and food source for other strombids (Stoner \& Waite 1990, Stoner \& Waite 1991). However the majority of seagrass at Cocos (Keeling) is in the southeastern part of the lagoon, an area that is exposed for prolonged periods at low tide and has patches of anoxic sediment. In addition, a previous study suggested that $L$. lambis may feed on fine red algae rather than on seagrass (Younge in Abbott 1961); therefore a negative correlation with seagrass appears reasonable. L. lambis may also be associated with macroalgae and hard macroalgae for shelter; most of the L. lambis counted were at least partially concealed by the macroalgae and could only be located by touch. L. lambis were also observed clustered around the edges of submassive corals (e.g. Porites) where they were inconspicuous.

The distance of the survey sites from Home Island, the island on which the Cocos Malay population resides, did not have a significant correlation with the density of Lambis lambis. In isolation this result may indicate that fishing pressure does not affect density as much as habitat type; however several other confounding factors need to be considered. (1) The Cocos Malay population tends to practice a system of rotational fishing where they fish an area intensively and then move to another once the density of L. lambis declines. Given the relatively small size of the lagoon $\left(\sim 100 \mathrm{~km}^{2}\right)$, this practice tends to spread fishing effort across the lagoon rather than concentrating it close to Home Island. (2) Most families own at least 1 boat, and fishing from boats is extremely popular as it provides easy access to most fishing and collecting areas throughout the la- 
goon, so not just areas close to Home Island are harvested (Lincoln-Smith et al. 1993).

The inclusion of spatial structure in the habitat modelling process greatly improved the predictive capacity of the model. Also, it provided an understanding of the relationship between habitat variables and the underlying spatial structure and how the habitat variables contributed to explaining Lambis lambis density. In the present study, density variation seemed to be determined by spatial scales operating at moderately broad to moderately fine levels. The lack of broad-scaled MEM variables in the spatial model suggests some habitat heterogeneity within the lagoon, whereas the lack of very fine-scaled MEMs reflects a relatively open system where highly patchy microhabitats do not develop. This result also indicates that the sampling design did not allow the detection of very fine-scaled patterns resulting from population-level processes

Approximately $56 \%$ of the variance explained by the environmental variables is shared by the selected spatial MEM eigenfunctions, indicating that these habitats occur largely at the intermediate scales modelled by the selected MEM variables. However, the selected habitat variables account for $\sim 35 \%$ of the explained variance independently of underlying spatial structure. This relatively high level of independence suggests that the distribution of these habitats may also reflect autonomous biotic interactions such as settlement and growth of the biota forming them.

However, $49 \%$ of the variation in Lambis lambis density remains unexplained. This unexplained variation might reflect autonomous biological characteristics of $L$. lambis such as their propensity to aggregate, unmeasured environmental variables that are important descriptors of $L$. lambis habitat, or patterns in the settlement of the recruits. Aggregation in strombids is well known, although the causes and advantages are not fully understood (Catterall \& Poiner 1983, Stoner \& Ray 1993, Ray \& Stoner 1994). Aggregation of Strombus gigas is a common phenomenon in important nursery areas (Stoner \& Ray 1993), while $S$. luhuanus frequently occurs in local aggregations with discrete boundaries (Catterall \& Poiner 1983). Personal observations of $L$. lambis at Cocos Keeling would also suggest that aggregation is a common phenomenon in this species. Had the sampling been denser spatially, we would expect the spatial model to contain very finescaled significant spatial variation resulting from the aggregation behaviour of L. lambis or other neutral processes acting at the population level (Alonso et al. 2006).

When Cocos Malays began collecting Lambis lambis is not known, but Gibson-Hill (1946) does not mention conch collection in his description of fishing activities in this area, which suggests that it is a relatively new fishery. Lincoln-Smith et al. (1993) estimated that between 40000 and $55000 \mathrm{~L}$. lambis were collected annually, weighing between about 2.2 and $3.2 \mathrm{t}$ (meat without shells). However, these estimates should be treated with caution because they are based on the impressions of the local community and have not been independently validated. Fishing for L. lambis occurs for about $10 \mathrm{~d}$ a month at low tide, usually in the morning (Parks Australia pers. comm.). Typically, between 200 and 1000 L. lambis are collected, if available. Up to several thousand are collected for special events such as the conclusion of Ramadan or weddings (Parks Australia pers. comm.). Large areas in the south and west of the lagoon are not presently fished for L. lambis. Similarly, because L. lambis are collected by wading and not by free or SCUBA diving as with other strombids (Tewfik \& Guzman 2003), areas that contained unexploited populations of $L$. lambis were thought to exist, particularly in deeper water. Deep-water refuges have been found in other strombid populations such as for Stombus luhuanus on the south coast of Papua New Guinea where overfishing has occurred in shallow water but deep-water populations have not been affected (Poiner \& Catterall 1988). However our results suggest that densities of L. lambis in the unfished areas were low due to unsuitable habitat, i.e. sand and seagrass, while deeper water areas ( $>2 \mathrm{~m}$ ) generally displayed low densities of L. lambis due to the lack of hard macroalgae. These findings correlate with previous descriptions of the marine habitats of the Cocos (Keeling) Islands that indicate the majority of macroalgae habitats are located in the shallow eastern portion of the lagoon (Williams 1994). Given the relationship between L. lambis and macroalgal habitats, the location of these habitats within the lagoon and the predominately shallow nature of the lagoon, the finding that few adult $L$. lambis are found in deeper waters $(>2 \mathrm{~m})$ is not surprising. However, while no refuge areas for adult $L$. lambis appeared to be present in the lagoon, juveniles are believed to live embedded in the sand until sexually mature, thus only the adult stage is ever harvested (Hender et al. 2001).

Spatial closures have been one of the most effective management tools for protecting queen conch populations (Tewfik \& Béné 2000). Spatial closures can protect spawning stocks at high densities and can be an important source of larvae and new recruits to exploited areas (Tewfik \& Béné 2003). In the Bahamas, the density of Strombus gigas was 31 times greater in no-take zones than in unprotected areas outside the park (Stoner \& Ray 1996). However the effectiveness of spatial closures for $S$. gigas depended on protecting critical habitats such as spawning sites and nursery grounds. Appeldoorn (1997) suggested that S. gigas stocks are largely dependent on self-recruitment, mak- 
ing the preservation of local stocks that much more important for sustainable management. Implementation of management measures to ensure sustainability of Lambis lambis populations at the Cocos (Keeling) Islands are especially important as it is an isolated atoll and sources of larvae from other areas are unlikely (Berry 1989). Spatial or temporal closures may be the simplest and most effective management measure for L. lambis, but an essential first step is to understand the relationship between the distribution and density of L. lambis and its preferred habitat. Given the results of this study, any spatial closures in this location would need to include intermediate levels of macroalgae and submassive coral. The fine to medium spatial scales of habitat classes that influence the distribution of L. lambis suggest that a number of moderately sized spatial closures would be required to support the recovery of L. lambis populations at the Cocos (Keeling) Islands.

Acknowledgements. This work was funded by the Attorney General's Office, Australian Government, which provided salaries for L.M.B. and S.N.E. as well as funding for project logistics. P.L. was supported by the Natural Sciences and Engineering Research Council of Canada (grant no. 7738) as well as through an appointment as a Distinguished Visiting Professor at the University of Western Australia. We are grateful to Parks Australia Cocos (Keeling) Islands, in particular I. Macrae, M. Said Chongkin and C. Boland for their advice and assistance in the field. We thank F. Webster and D. Gerhard (Cocos Dive) for their invaluable assistance. We also thank the residents of the Cocos (Keeling) Islands who provided advice and assistance. Finally, the paper was greatly improved by thoughtful comments from 3 anonymous reviewers.

\section{LITERATURE CITED}

Abbott RT (1961) The genus Lambis in the Indo-Pacific. IndoPacific Mollusca 1:147-174

Alonso D, Etienne RS, McKane AJ (2006) The merits of neutral theory. Trends Ecol Evol 21:451-457

Appeldoorn RS (1997) Status of Queen Conch fishery in the Caribbean Sea. In: Posada JM, Garcia-Moliner G (eds) Proc Int Queen Conch Conf. Caribbean Fishery Management Council, San Juan

Bejarano S, Mumby PJ, Sotheran I (2011) Predicting structural complexity of reefs and fish abundance using acoustic remote sensing (RoxAnn). Mar Biol 158:489-504

Bellchambers LM, Evans SN, Meeuwig JJ (2010) Abundance and size of western rock lobster (Panulirus cygnus) as a function of benthic habitat: implications for ecosystembased fisheries management. Mar Freshw Res 61:279-287

Berry PF (1989) Survey of the marine fauna of Cocos (Keeling) Islands, Indian Ocean. Western Australian Museum, Perth

Borcard D, Legendre P (2002) All-scale spatial analysis of ecological data by means of principal coordinates of neighbour matrices. Ecol Model 153:51-68

Borcard D, Legendre P, Drapeau P (1992) Partialling out the spatial component of ecological variation. Ecology 73: 1045-1055

Borcard D, Legendre P, Avois-Jacquet C, Tuomisto H (2004) Dissecting the spatial structure of ecological data at multiple scales. Ecology 85:1826-1832

Catterall CP, Poiner IR (1983) Age- and sex-dependent patterns of aggregation in the tropical gastropod Strombus luhnanus. Mar Biol 77:171-182

> Dray S, Legendre P, Peres-Neto PR (2006) Spatial modelling: a comprehensive framework for principal coordinate analysis of neighbour matrices (PCNM). Ecol Model 196: 483-493

> Freeman SM, Rogers SI (2003) A new analytical approach to the characterisation of macro-epibenthic habitats: linking species to the environment. Estuar Coast Shelf Sci 56: 749-764

Gibson-Hill CA (1946) Boats and fishing on the Cocos-Keeling Islands. J R Anthropol Inst G 76:13-23

Harper SJM, Bates CR, Guzman HM, Mair JM (2010) Acoustic mapping of fish aggregation areas to improve fisheries management in Las Perlas Archipelago, Pacific Panama. Ocean Coast Manag 53:615-623

Hender J, McDonald CA, Gilligan JJ (2001) Baseline survey of marine environments and stock size estimates of marine resources of the South Cocos (Keeling) Atoll (0-15m), Eastern Indian Ocean. Fish Resour Res Fund Annu Rep. Agriculture, Fisheries and Forestry, Canberra

Legendre P, Legendre L (1998) Numerical ecology, 2nd English edn. Elsevier Science BV, Amsterdam

Lincoln-Smith MP, Underwood AJ, Smith AK, Hawes PMH and others (1993) A study of the impact of harvesting marine invertebrate and fish on the marine ecosystems of Cocos (Keeling) Islands, Indian Ocean. The Institute of Marine Ecology, The University of Sydney, Sydney

Moore CH, Harvey EJ, Van Niel K (2010) The application of predicted habitat models to investigate the spatial ecology of demersal fish assemblages. Mar Biol 157:2717-2729

O'Connor S, Spriggs M, Veth P (2002) Excavation at Lene Hara Cave establishes occupation in East Timor at least 30,000-35, 000 years ago. Antiquity 291:45-49

Ohtani K (2000) Bootstrapping $R^{2}$ and adjusted $R^{2}$ in regression analysis. Econ Model 17:473-483

> Peres-Neto PR, Legendre P (2010) Estimating and controlling for spatial structure in the study of ecological communities. Global Ecol Biogeogr 19:174-184

Peres-Neto PR, Legendre P, Dray S, Borcard D (2006) Variation partitioning of species data matrices: estimation and comparison of fractions. Ecology 87:2614-2625

Poiner IR, Catterall CP (1988) The effect of traditional gathering on populations of the marine gastropod Strombus luhuanus linne 1758, in southern Papua New Guinea. Oecologia 76:191-199

Ray M, Stoner AW (1994) Experimental analysis of growth and survivorship in a marine gastropod aggregation: balancing growth with safety in numbers. Mar Ecol Prog Ser 105:47-59

R Development Core Team (2009) R: a language and environment for statistical computing. R Foundation for Statistical Computing, Vienna. www.R-project.org (accessed 20 Dec 2009)

Stoner AW (2003) What constitutes essential nursery habitat for a marine species? A case study of habitat form and function for queen conch. Mar Ecol Prog Ser 257:275-289

Stoner AW, Ray M (1993) Aggregation dynamics in juvenile queen conch (Strombus gigas): population structure, mortality, growth, and migration. Mar Biol 116:571-582

Stoner AW, Ray M (1996) Queen conch, Strombus gigas, in fished and unfished locations of the Bahamas: effects of a marine fishery reserve on adults, juveniles and larval production. Fish Bull 94:551-565

Stoner AW, Waite JM (1990) Distribution and behavior of 
queen conch Strombus gigas relative to seagrass standing crop. Fish Bull 88:573-585

Stoner AW, Waite JM (1991) Trophic biology of Strombus gigas in nursery habitats: diets and food sources in seagrass meadows. J Molluscan Stud 57:451-460

Tewfik A, Béné C (2000) Densities and age structure of fished versus protected populations of queen conch (Strombus gigas L.) in the Turks and Caicos Islands. Proc Gulf Caribb Fish Inst 51:60-79

Tewfik A, Béné C (2003) Effects of natural barriers on the spillover of a marine mollusc: implications for fisheries reserves. Aquat Conserv 13:473-488

Tewfik A, Guzman HM (2003) Shallow-water distribution and population characteristics of Strombus gigas and $S$. costa-

Editorial responsibility: Romuald Lipcius,

Gloucester Point, Virginia, USA tus (Gastropoda: Strombidae) in Bocas del Toro, Panama. J Shellfish Res 22:789-794

Theile S (2003) Queen conch fisheries and their management in the Caribbean. TRAFFIC Europe

Torres Rosado ZA (1987) Distribution of two mesogastropods, the queen conch, Strombus gigas Linnaeus, and the milk conch, Strombus costatus Gmelin, in La Parguera, Lajas, Puerto Rico. MS thesis, University of Puerto Rico, Puerto Rico

Williams DG (1994) Marine habitats of the Cocos (Keeling) Islands. In: Woodroffe CD (ed) Ecology and Geomorphology of the Cocos (Keeling) Islands. Atoll Research Bulletin 406. National Museum of Natural History, Smithsonian Institution, Washington DC

Submitted: June 4, 2010; Accepted: March 25, 2011

Proofs received from author(s): June 1, 2011 